\title{
A CASE OF CONGENITAL HEMIHYPERTROPHY SHOWING VARIATIONS IN BONE AGE AND DEVELOPMENT
}

\author{
BY \\ F. STEPHEN CARTER and G. C. DOCKERAY \\ From King George VI Hospital, Nairobi, and the Medical Research Laboratory, Nairobi
}

(RECEIVED FOR PUBLICATION MARCH 13, 1953)

Although the ancient Greek and Roman sculptors recognized that the human frame was not symmetrical, it was not until 1822 that Meckel pointed out variations in size and shape of the two halves of the body, and the first clinical report of a patient with hemihypertrophy was made by Wagner in 1839 . Since that day there have been only just over 100 cases reported throughout the world claiming total hemihypertrophy, and this is probably in excess of the truth if the name given to the condition is taken literally. Ward and Lerner (1947), in reviewing the case reports, state that necropsies had been recorded in only seven cases, and they added a case report of their own with necropsy findings, and concluded, according to their classification of hypertrophy, that their patient had congenital total hemihypertrophy. It is doubtful, however, if this claim can be accepted, as one set of paired organs, namely, the kidneys, was equal in size, and the two lobes of the thyroid were also apparently equal. In the absence of a necropsy, the diagnosis of congenital total hemihypertrophy has to be made on external appearances, with the assumption that the internal paired organs will also show hypertrophy on the affected side. That this assumption may be false is shown by the case quoted above, and also by the necropsy findings of the case recorded in this paper.

The chief interest in this case, however, lies in the radiological appearances of the wrists and hands, which show well marked differences in the extent of ossification of the carpal nuclei on the two sides, and also structural abnormality of the bones themelves.

\section{Case Report}

A male infant, said to be 18 months old, of the Munyore tribe, from the North Nyanza Province of Kenya, was referred from one of the City African child welfare clinics in Nairobi to King George VI Hospital on June 20,1952, for investigation of his asymmetrical development and treatment for gastro-enteritis.
On examination, the face appeared symmetrical, but there was obvious enlargement of the left side of the body, apparently involving all the component parts. The skin of the left limbs was somewhat coarser than that of the right, and this impression was enhanced by an increase of subcutaneous tissue on the affected side. The muscle substance was increased on the left side, and this was most marked in the deltoid, triceps and biceps in the arms, and the gluteal group in the legs, although hypertrophy was evident throughout the smaller muscle groups in both the upper and lower limbs.

The infant suffered from frequent attacks of petit mal. There would be a sudden cessation of activity, his facial expression would become vacant, and his eyes take on a glassy appearance. This period of inactivity usually lasted only a few seconds, but on two occasions it was reported to have lasted for about a minute, causing considerable anxiety to the ward staff. On no occasion was an attack of grand mal, or Jacksonian epilepsy, witnessed.

After an initial response to therapy for the gastroenteritis, there was a sudden relapse and death occurred within a few hours, despite resuscitative measures.

During the period of remission the infant's behaviour was considered to be somewhat retarded for his age, but he could not be considered an obviously mentally defective child. Despite the disproportion of his lower limbs, he was frequently to be seen standing up in his cot, and he appeared to be taking a reasonable interest in ward activities. There was, however, a certain dullness in his facial expression and a lack of alertness, but this could partly be attributed to the intercurrent infection. His powers of walking were not assessed, but there was a well marked compensatory scoliosis when he stood up in his cot.

Necropsy Findings. At necropsy, hypertrophy of the left side of the body, from the neck downwards, was confirmed. The difference in size of the various muscle groups was very obvious on dissection of the two sides. The long bones were excised and measured (Fig. 1 and Table 1). The only paired internal organs to show any noticeable difference in size were the kidneys, the left weighing $44 \mathrm{~g}$. and the right $30 \mathrm{~g}$. There was also a slight difference in weight of the two lungs, the left weighing $81 \mathrm{~g}$., and the right $75 \mathrm{~g}$., whereas the right lung is normally the 
heavier of the two. In adults, the right lung varies from 480 to $680 \mathrm{~g}$., and the left from 420 to $600 \mathrm{~g}$. (Mallory, 1938).

The cerebral hemispheres, lobes of the thyroid, suprarenals and testes appeared equal on the two sides. The degree of dental eruption was the same on both sides, and there was no evidence of inequality of the two sides of the tongue.

TABLE 1

MEASUREMENTS OBTAINED FROM POST-MORTEM MATERIAL

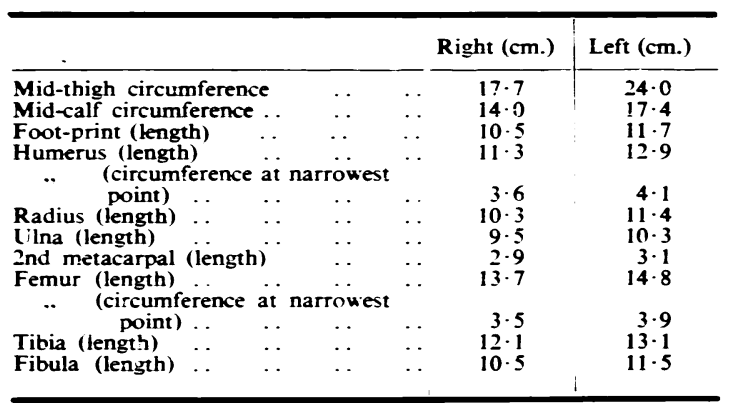

* Bone measurements include epiphyseal cartilages.

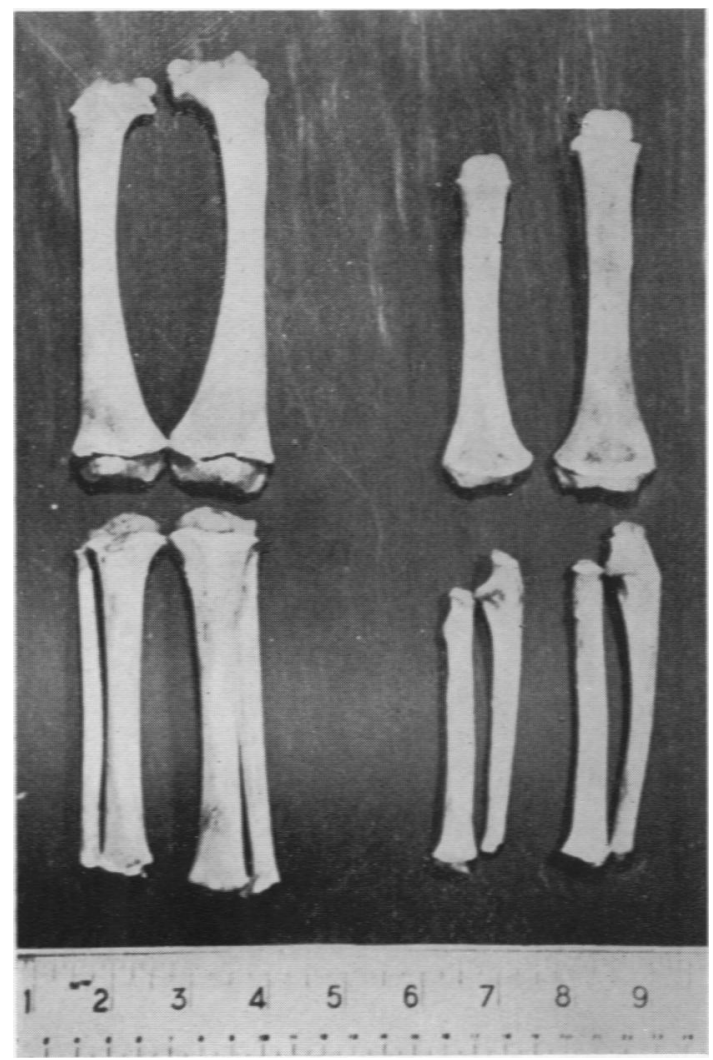

Fk. 1.-Photograph of the long bones, excised at necropsy, showing hypertrophy of those on the left side of the body.
Radiological Findings. Radiographic examination of the skull showed no abnormality, and the sella turcica was well within normal limits. Dental development was equal on both sides. The radiological appearance of the long bones and pelvis showed considerable hypertrophy on the affected side, and the wrists showed evidence of variation in bone age (Figs. 2 and 3).

Dr. W. G. S. Hopkirk kindly examined the radio-

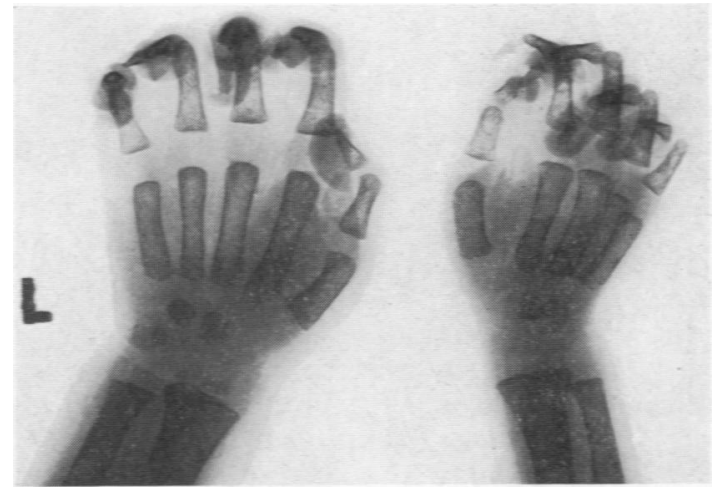

Fig. 2.-Radiograph of both wrists. Left wrist shows well developed centres of ossification for the capitate, hamate, triquetrum, and inferior radial epiphysis. Right wrist show's only the capitate and hamate, atthough a minute centre of ossification for the triquetrum is visible on the original radiograph.

graphs of the wrists, and gives the following report on the bone age, based on the studies of Mackay (1952) for African children:

\begin{tabular}{|c|c|}
\hline Right Wrist & Left $\mathbf{w}_{\text {rist }}$ \\
\hline $\begin{array}{l}\text { Carpus (if tiny triquetral centre is disregarded) } \\
18 \text { months } \\
\text { Inferior radial epiphysis, still absent. Less } \\
\text { than } 18 \text { months }\end{array}$ & $\begin{array}{l}3 \text { years } 6 \text { months } \\
\text { Present } 18 \text { months }\end{array}$ \\
\hline Metacarpal diaphyses, 18 months & 2 years 6 months \\
\hline
\end{tabular}

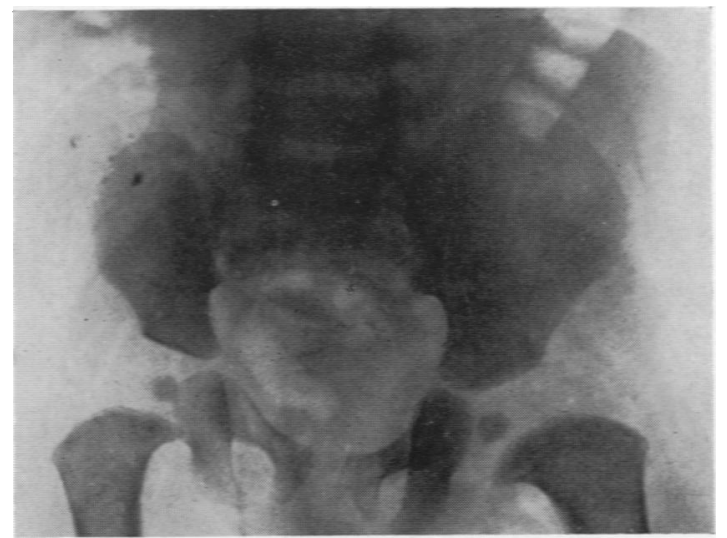

FiG. 3.-Radiograph of the pelvis. showing considerable enlargement of the left ilium, and increased depth of the soft tissues on the left side. 
Dr. Hopkirk also reports that... the structure of the metacarpals, and to a lesser extent of the radius and ulna, is not normal. There is less individual shaping than would be expected from the known age, and the appearances suggest that there has been slight cortical atrophy from within and a lack of normal trabecular formation. This suggests some hypertrophy of the bone marrow, though not to the extent often seen in severe haemolytic anaemias ... Epiphyseal development is retarded very considerably ... Having regard to the absence of the metacarpal and phalangeal epiphyses the bone age on both sides should be about 1 year.'

\section{Discussion}

There has been much speculation as to the aetiology of congenital hemihypertrophy, and the various theories were reviewed by Schwartzman, Grossman and Dragutsky (1942). Endocrine imbalance, congenital syphilis, vascular lesions, lesions of the brain, and embryonic defects of the vegetative nervous system, have all had their advocates, but the theory propounded by Gesell (1927), is the one to which most credence is given among the more recent authors. Gesell considered that the condition was due to an atypical form of twinning occurring in the very earliest divisions of the fertilized ovum. Asymmetry was described in a $10 \mathrm{~mm}$. human embryo by Phisalix in 1888 .

Campbell (1923) described a case of hypertrophy due to neurofibromatosis, and cases have been recorded by McFarland (1928) and Williams (1951) where the condition was due to abnormalities of the lymphatic system, although the latter case also showed hypertrophy of the bones of the right forearm and hand.

The frequency with which other congenital abnormalities coexist with congenital hemihypertrophy has been put as high as $50 \%$ by Ward and Lerner (1947). The commonest lesions are cutaneous naevi and telangiectases, mental deficiency being the next most frequent. Gesell (1927) collected 53 cases of congenital hemihypertrophy, and eight of these were mentally defective. Lenstrup (1927) published a series of eight cases, one of which was mentally defective, and another suffered from convulsions. Other authors have recorded cases of mental deficiency, and the frequency with which it occurs has been estimated at 15 to $20 \%$ (Wakefield and Hines, 1933; Schwartzman et al., 1942). Other congenital abnormalities that have been described include congenital heart disease, hypospadias, cryptorchidism, supernumerary nipple, polydactylism, synostosis, and total absence of the thyroid. The affected side of the body may also show thickening of the hair, premature eruption of the teeth, abnormal growth of the nails and excessive sweating.
In the case recorded here no anatomical congenital abnormalities were discovered, but the degree of intelligence was considered to be low, and the infant also suffered from numerous attacks of petit mal.

Heredity appears to have no influence in the great majority of cases (Worster-Drought, 1951), but a high proportion of siblings may show other congenital abnormalities (Halperin, 1931). Hemihypertrophy has, however, been described in a mother and daughter (Scott, 1935), and also in a brother and sister (Reed, 1925).

The literature on the subject of hemihypertrophy contains a number of references to radiological enlargement of the bones on the affected side. In the series of eight cases described by Lenstrup (1927), three of them showed radiological enlargement of the bones, but an increase in bone age on the affected side appears to occur infrequently, as only two such cases have been found recorded (Scott, 1935; Williams, 1951). Gesell (1927), however, included in his case report of a girl of 2 years old a reproduction of a radiograph showing the centre of ossification for the semilunar bone on the affected side, which was absent on the normal side. This fact is recorded in a table of measurements, but no comment is made in the script. It is probable that advancement of bone age occurs more frequently than is recorded as many cases had reached bone maturity before being investigated. Worster-Drought (1952) comments that . . enlargement, whether hemihypertrophy or merely hypertrophy of one limb, can include advanced bone age, that is as compared with the opposite and normal side, while other cases show merely enlargement without apparent advance in bone age' . . .

Dr. J. F. Brailsford, who has also studied the radiographs in this case, states:

'The bones of the hands do not show normal architecture. They have not the exquisite shape of the normal; the cortical compact tissue is reduced to linear proportions: the cancellous structure is of a coarser mesh, which is defective. These features suggest an established disturbance in ossification such as we see in congenital anaemias.

The right hand shows a stage of ossification of the carpus which is in agreement with the normal, but lack of ossification in the epiphyses of the metacarpals and the radius suggests delay.

The hypertrophied left hand shows bones which are all some degree larger than the right; the ossification of the carpals is in advance of the normal but this is not supported by the lack of ossification in the epiphyses of the metacarpals and phalanges.

The case clearly indicates that the times for ossification of the epiphyses and the carpal nuclei are variable, and considerable latitude must be allowed in estimating bone age from either. So many factors influence early ossification but do not neces- 
sarily influence the carpal nuclei to the same degree as the metacarpal and phalangeal epiphyseal nuclei. Inflammatory processes can cause delay in ossification yet it would seem that an increased blood supply to a limb appears to advance the ossification beyond that of the opposite limb, but here we see evidence of advance of the carpal but delay in the metacarpal and phalangeal-a clear indication that our knowledge of growth is very defective . . .

Another feature of interest found at necropsy concerned the size of the various 'paired' internal organs. Although there was radiological evidence of skeletal hypertrophy of ribs and pelvis as well as both upper and lower limbs on the left side, yet the testes and suprarenals were of the same size on both sides of the body. Ward and Lerner (1947) had a similar experience when, at the necropsy of a patient who had apparently congenital total hemihypertrophy, they found the kidneys to be equal in size, and the lobes of the thyroid also appeared identical.

If the theory is accepted that hemihypertrophy is due to an abnormal form of twinning at a very early stage after fertilization of the ovum, it would seem reasonable to expect the hypertrophy to involve all the structures within the embryological segments so affected. It is apparent that this is not always so, and therefore it is obviously unwise to assume congenital total hemihypertrophy on external appearances alone, as this is the second case out of a total of nine necropsies recorded in the literature where equality of such paired organs has been found.

\section{Summary}

A case of left-sided congenital hemihypertrophy with necropsy findings is reported.
Radiologically, the carpal bones showed apparent advancement of bone age on the affected side, but also retardation in development of the epiphyses of the metacarpals and phalanges on the same side, combined with an abnormal structure of the bones themselves.

As certain internal paired organs within the embryological segments affected by the hypertrophy were found to be equal in size at necropsy, namely, testes and suprarenal glands, it is considered unwise to assume a diagnosis of congenital total hemihypertrophy on external appearances alone.

We are indebted to the Hon. Director of Medical Services, Kenya, for permission to publish this paper. We also wish to express our thanks to Dr. W. G. S. Hopkirk and Dr. J. F. Brailsford for their assistance and interpretation of the radiographs, and to Dr. J. A. T. Henry, who referred the child to us in the first instance.

\section{RFFERENCES}

Campbell, W. C. (1923). Surg. Gynec. Obstet., 36, 699.

Gesell, Arnold (1927). Amer. J. med. Sci., 173, 542

Halperin, G. (1931). Arch. intern. Med., 48, 676.

Lenstrup, E. (1927). Acta paediat., Uppsala, 6, 205

Mackay, D. H. (1952). Trans. roy. Soc. trop. Med. Hyg., 46, 135

Mallory, F. B. (1938). Pathological Technique, p. 375. Philadelphia.

McFarland, B. L. (1928). Brit. med. J., 1, 345.

Meckel, J. F. (1822). Quoted by Halperin (1931).

- Phisalix, C. (1888). Arch. Zool. exp. gén., ser. 2, 6, 279. Quoted by Wakefield and Hines (1933).

Reed, E. A. (1925). Arch. Neurd. Psychiat., Chicago, 14, 824.

Schwartzman, J., Grossman, L. and Dragutsky, D. (1942). Arch. Pediat., 59, 637.

Scott, A. J. (1935). J. Pediat., 6, 650.

Wagner, H. (1839.) Quoted by Schwartzman et al. (1942).

Wakefield, E. G. and Hines, E. A. (1933). Amer. J. med. Sci., 185, 493.

Ward, J. and Lemer, H. H. (1947). J. Pediat., 31, 403.

Williams, J. Aled (1951). Archives of Disease in Childhood, 26, 158.

Worster-Drought, C. (1951). The British Encyclopaedia of Medical Practice, 2nd ed., vol. 6, p. 464. London. 